\title{
CX. A NEW SYNTHESIS OF METHIONINE.
}

\author{
By GEORGE BARGER \\ AND THEODORE EDWIN WEICHSELBAUM. \\ From the Department of Medical Chemistry, University of Edinburgh.
}

(Received May 21st, 1931.)

THE Strecker synthesis of methionine by Barger and Coyne [1928] served its purpose in establishing the constitution of the amino-acid, but the yield (6\%, based on the $\beta$-methylthiolpropaldehyde employed) did not help to make the substance more easily available than the natural product, which is very troublesome to isolate. A second synthesis by Windus and Marvel [1930] (bromination of $\beta$-methylthiolethylmalonic acid) did not result in a greatly improved yield ( $7 \%$ based on the $\alpha$-methylthiol- $\beta$-chloroethane employed), probably owing to the oxidation of the methylthiol group.

In order to render the amino-acid more readily available for metabolic studies and for investigation of its optical properties, we thought it desirable to explore other possible syntheses with a view to obtaining increased yields. The synthesis described in this paper avoids the main difficulties of the preceding ones, namely the use of a rather inaccessible intermediate, acrolein, and the oxidation of the methylthiol group by bromination. By its use we have been able to accumulate a considerable supply of methionine and at present we are engaged in its resolution. It will be recalled that the method for the isolation of the naturally occurring substance involves the use of alkali under conditions which probably lead to at least partial racemisation.

Following the lines which led Sørensen [1903-6] to the synthesis of $\alpha$-aminoadipic acid and other amino-acids, ethyl sodiophthalimidomalonate was made to react with $\alpha$-methylthiol- $\beta$-chloroethane. On hydrolysis of the resulting compound (I), first with alkali to the phthalamidomalonic acid (II) and then with acid, methionine (III) was obtained in a yield of $58 \%$ (based on the $\alpha$-methylthiol- $\beta$-chloroethane employed). The reactions are represented by the following equations:

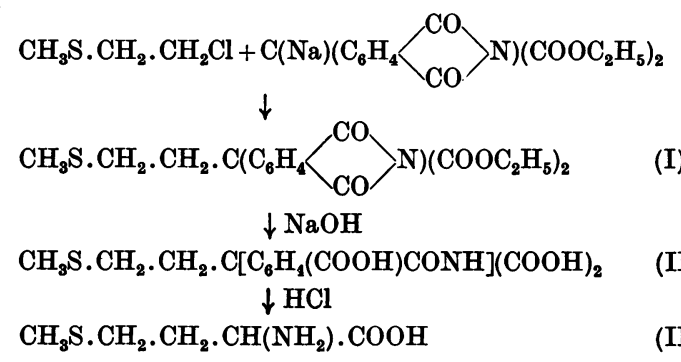




\section{EXPERIMENTAL.}

$\alpha$-Methylthiol- $\beta$-chloroethane. $440 \mathrm{~g}$. of methyl isothiocarbamide sulphate, prepared according to the method of Arndt [1921] in a yield of $95 \%$, were hydrolysed by $670 \mathrm{cc}$. of $5 \mathrm{~N}$ sodium hydroxide and the methylmercaptan obtained was directly absorbed in a solution of $5.5 \mathrm{~g}$. of sodium in $1185 \mathrm{cc}$. of commercial alcohol. This solution was heated to boiling and $207 \mathrm{~g}$. of ethylene chlorohydrin were added in such a manner that the solution continued to reflux gently. After the addition of the ethylene chlorohydrin the solution was boiled for 10 hours. It was found inadvisable to distil the alcohol from the solution since the large amount of sodium chloride present caused considerable danger of breakage from bumping. The solution was centrifuged and the salt shaken up with successive quantities of absolute alcohol until it retained no appreciable odour of the thiol compound. The alcoholic solution of the thiol compound was then distilled in vacuo, the yield of $\alpha$-methylthiol- $\beta$-hydroxyethane being $126 \mathrm{~g}$. of a product boiling at $59^{\circ}-70^{\circ} / 16 \mathrm{~mm}$. (51\% of the theory based on the ethylene chlorohydrin employed).

The $\alpha$-methylthiol- $\beta$-hydroxyethane was chlorinated by the method of Bennett [1929]. $318 \mathrm{~g}$. of thionyl chloride were dissolved in $700 \mathrm{~g}$. of dry chloroform and the solution was added drop by drop to the dimethylaniline solution of the thiol compound. The solution was kept at room temperature for 2 hours and then heated for 20 minutes on the steam-bath. It was then washed three times with concentrated hydrochloric acid and twice with water, dried over calcium chloride, filtered, and freed from chloroform by distillation. The residue of crude chlorosulphide was distilled in vacuo. The yield was $115 \mathrm{~g}$. of a product boiling at $50^{\circ} / 25 \mathrm{~mm}$. (70\% of the theory).

Ethyl sodiophthalimidomalonate [Sørensen, 1905]. To a solution of $4 \cdot 6 \mathrm{~g}$. of clean sodium in $150 \mathrm{cc}$. of absolute alcohol (freshly distilled over sodium) at about $60^{\circ}, 63 \mathrm{~g}$. of ethyl phthalimidomalonate [Sørensen, 1903-6; Organic Syntheses, 1927] were added and the mixture was shaken. The sodium compound, which crystallised on cooling in ice-water, was filtered quickly at the pump, washed twice with absolute alcohol and twice with absolute ether and dried in a vacuum desiccator over sulphuric acid. The yield was $67 \mathrm{~g}$., and by neutralisation of the mother-liquors with hydrochloric acid $5.5 \mathrm{~g}$. of the ester were recovered. A sample of the sodium compound was dried to constant weight at $140^{\circ} / 10 \mathrm{~mm}$, and in 6 hours lost $16.8 \%$ of its weight ( $1 \frac{1}{2}$ molecules of alcohol of crystallisation require $17 \cdot 43 \%$ loss); the colour of the substance changed on drying from a rather deep orange-yellow to a very light yellow. This colour change can be used as an index of the completion of the drying of large quantities of the compound, which is essential if one wishes to obtain the highest yield possible in the subsequent step, and this was accomplished by heating in a bolt-head flask in an oil-bath at $145-155^{\circ} / 12 \mathrm{~mm}$. with occasional shaking for 8 hours or until the change of colour of the substance to light yellow was complete.

(Found: $7.036 \%$ Na. Calculated for $\mathrm{C}_{15} \mathrm{H}_{14} \mathrm{O}_{6} \mathrm{NNa}: 7.04 \% \mathrm{Na}$.) 
In order to avoid the inconvenience of having to rid the substance of its alcohol of crystallisation, the method of Dunn and Smart [1930] may be used.

Ethyl $\beta$-methylthiol- $\alpha$-phthalimidoethylmalonate (I). $85 \mathrm{~g}$. of the ethyl sodiophthalimidomalonate were placed in a 250 cc. bolt-head flask fitted with a 3 -holed rubber stopper for condenser, thermometer and stoppered glass tube for sampling; $43 \mathrm{~g}$. of $\alpha$-methylthiol- $\beta$-chloroethane ( $60 \%$ excess) were added and the flask was heated in an oil-bath at $150^{\circ}$ until the reaction mixture was no longer alkaline to turmeric paper (in this case the time was 1 hour and 45 minutes). The excess of the chloro-compound was distilled off in vacuo (after redistillation $12 \mathrm{~g}$. of a pure product were obtained). The residual yellow oil was mixed with warm water and poured into an evaporating dish where it almost immediately crystallised. The crystalline substance was again extracted with water to remove any remaining sodium chloride and recrystallised from the smallest quantity of alcohol possible. It formed white prisms having M.P. $67^{\circ}$ (uncorr.). The yield was $79 \mathrm{~g}$. ( $74 \%$ of the theory, based on the chloro-compound used).

(Found: $56.96 \%$ C, $5.52 \% \mathrm{H}, 8.53 \%$ S. Calculated for $\mathrm{C}_{18} \mathrm{H}_{21} \mathrm{O}_{6} \mathrm{NS}$ : $57 \cdot 14 \%$ C, $5 \cdot 58 \% \mathrm{H}, 8 \cdot 44 \%$ S.)

$\beta$-Methylthiol- $\alpha$-phthalamidoethylmalonic acid (II). $25 \mathrm{~g}$. of the ester were dissolved in $30 \mathrm{cc}$. of alcohol in a $200 \mathrm{cc}$. bolt-head flask, placed on a boiling water-bath and $70 \mathrm{cc}$. of $5 \mathrm{~N}$ sodium hydroxide were added. The cloudy liquid was heated until a sample gave a clear solution when diluted with water. The sodium salt of the acid is insoluble in an excess of sodium hydroxide but very soluble in water. For the preparation of methionine it was unnecessary to isolate the free acid, though this was actually done. After the hydrolysis was completed the solution was cooled to $0^{\circ}$ in an ice-salt mixture and carefully neutralised with $0.2 \mathrm{~N}$ hydrochloric acid to Congo red paper. To this solution, still at $0^{\circ}, 75 \mathrm{cc}$. of $5 \mathrm{~N}$ hydrochloric acid were added carefully, during which process the acid began to separate in the form of white crystals. In order to complete the salting-out $60 \mathrm{cc}$. of concentrated hydrochloric acid were added slowly. The white crystalline mass was then filtered at the pump and freed from salt by trituration with ice-cold water. The yield was $21.5 \mathrm{~g}$. and $0.5 \mathrm{~g}$. more was obtained by working up the mother-liquors $(97 \%$ of the theory). M.P. $142-143^{\circ}$ (uncorr.).

(Found: $49.55 \% \mathrm{C}, 4.78 \% \mathrm{H}, 9.56 \%$ S. Calculated for $\mathrm{C}_{14} \mathrm{H}_{15} \mathrm{O}_{7} \mathrm{NS}$ : $49 \cdot 27 \%$ C, $4.40 \% \mathrm{H}, 9 \cdot 38 \%$ S.)

Methionine (III). $21.5 \mathrm{~g}$. of the above acid were suspended in $350 \mathrm{cc}$. of water in a litre flask which was then placed on a boiling water-bath. $40 \mathrm{cc}$. of concentrated hydrochloric acid were added. Almost immediately carbon dioxide was given off and the substance began to go into solution. The heating was continued for about $1 \frac{1}{2}$ hours and $200 \mathrm{cc}$. more of concentrated hydrochloric acid were added which did not produce a further precipitate. Heating was continued for 45 minutes to complete the reaction. The water and acid were then removed by distillation first at ordinary pressure and then in vacuo. 
The residue was taken up in warm water, $18 \mathrm{cc}$. of pyridine were added and three volumes of hot alcohol. On cooling the methionine separated as white crystals. The methionine was then suspended in $200 \mathrm{cc}$. of boiling absolute ether in order to remove any remaining phthalic acid, filtered at the pump and dried in a vacuum desiccator over sulphuric acid. M.P. $279^{\circ}-280^{\circ}$ (uncorr.). The yield was $8 \mathrm{~g}$. ( $81 \%$ of the theory based on the $\alpha$-methylthiolphthalamidoethylmalonic acid employed, or $58 \%$ of the theory based on the $\alpha$-methylthiol- $\beta$-chloroethane).

(Found: $40.47 \% \mathrm{C}, 7 \cdot 29 \% \mathrm{H}, 21 \cdot 46 \% \mathrm{~S}$. Calculated for $\mathrm{C}_{5} \mathrm{H}_{11} \mathrm{O}_{2} \mathrm{NS}$ : $40 \cdot 23 \%$ C, $7 \cdot 43 \% \mathrm{H}, 21.50 \% \mathrm{~S}$.)

Methionine methyl ester hydrochloride. A suspension of $2 \mathrm{~g}$. of methionine in 125 cc. absolute methyl alcohol, cooled in an ice-salt mixture, was saturated with hydrogen chloride for 2 hours. The alcohol and hydrochloric acid were then distilled off in vacuo. The residue was taken up in acetone from which it crystallised after 1 day in a vacuum desiccator. The ester hydrochloride was filtered off and washed with a small quantity of absolute ether. The yield was 1.9 g. (71 \% of the theory) of white needle-like crystals. M.P. $135^{\circ}$.

(Found: $17 \cdot 74 \% \mathrm{Cl}$. Calculated for $\mathrm{C}_{6} \mathrm{H}_{14} \mathrm{O}_{2} \mathrm{NSCl}: 17 \cdot 59 \% \mathrm{Cl}$.)

We gratefully acknowledge a grant from the Moray Fund of Edinburgh University which partially defrayed the expenses of this investigation.

\section{REFERENCES.}

Arndt (1921). Ber. deutsch. chem. Ges. 54, 2236.

Barger and Coyne (1928). Biochem. J. 22, 1417.

Bennett (1929). J. Chem. Soc. 2567.

Dunn and Smart (1930). J. Biol. Chem. 89, 46.

Organic Syntheses (1927), 7, 78 (New York).

Sørensen (1903-6). Compt. Rend. Trav. Lab. Carlsberg, 6, 1. (1905). Z. physiol. Chem. 44, 448.

Windus and Marvel (1930). J. Amer. Chem. Soc. 52, 2575. 